\title{
ALBUM ILUSTRADO Y TRABAJO COOPERATIVO: LAS PERCEPCIONES EN EDUCACIÓN INFANTIL
}

\section{Inmaculada Mena-Bernal Rosales}

\section{RESUMEN}

Este artículo explica la experiencia didáctica realizada con niños de Educación infantil, de 5 años, del Colegio San José (Sevilla), a partir del álbum ilustrado Sopa de Calabaza, de Helen Cooper. La metodología que se pone en práctica comienza con la realización de una rutina de pensamiento (see, think, wonder), seguida de la narración del cuento y desarrollo de la estructura de trabajo cooperativo del folio giratorio, para finalizar con la exposición a la clase de los dibujos realizados por cada grupo. El objetivo es demostrar la importancia de identificar, verbalizar y reflexionar sobre las percepciones en la didáctica de la lectura comprensiva a través de la Literatura Infantil, y la capacidad de esta metodología de potenciarla, y cómo de esta forma se estimula la motivación a la lectura y el interés por lo escrito.

Palabras clave: Literatura Infantil, álbum ilustrado, percepciones, trabajo cooperativo, rutina de pensamiento

\section{TITLE: PICTURE BOOKS AND COOPERATIVE WORK: PERCEPTIONS IN INFANT EDUCATION.}

\section{ABSTRACT}

This article explains the didactic experience carried out with Infant school children aged five in San José school, Seville, originating in the picture book Pumpkin Soup, by Helen Cooper. The methodology carried out began with routine thinking (see, think, wonder) followed by telling the story and the development of the structured cooperative work through rotating sheets of paper, ending with an exposition in class of the drawings done in each group. The objective is to demonstrate the importance of identifying, verbalizing, and reflecting on the perceptions in the didactics of comprehensive reading through Children's Literature and the capacity of this method to promote it, and how, in this way, motivational reading and interest in writing are stimulated.

Keywords: Children's literature, Picture Book, Perceptions, Cooperative Work, Routine Thinking.

Correspondencia con la autora Inmaculada Mena-Bernal Rosales. <mmena@ceuandalucia.es>. Centro de Estudios Universitarios Cardenal Spínola CEU. Original recibido: 23-05-16. Original aceptado: 07-10-16 


\section{Introducción}

El cuento es uno de los elementos fundamentales a través del cual el niño, a la par que disfruta, va adquiriendo la capacidad de nombrar no solo lo que ve, sino también lo que percibe y siente. Se convierte en canal de comunicación, en la puerta que le da acceso a la realidad a través de las narraciones e imágenes que se ponen a su alcance.

Si nos centramos en la definición que Mendoza Fillola nos ofrece, podemos entender la Literatura Infantil (en lo sucesivo, LI) como un conjunto de producciones de signo artístico y literario, de rasgos comunes y compartidos con otras producciones literarias -también con producciones de otros códigos semióticos- a las que se tiene acceso en tempranas etapas de formación lingüística y cultural (Mendoza, 1999, p. II).

Esta definición, que resume su perfil lingüístico, podemos completarla con la caracterización que nos acerca Teresa Colomer:

El objetivo de la educación literaria es, en primer lugar, el de contribuir a la formación de la persona, formación indisolublemente ligada a la construcción de la sociabilidad y realizada a través de la confrontación con textos que explicitan la forma en la que generaciones anteriores y la contemporánea han abordado y abordan la valoración de la actividad humana a través del lenguaje (...). La evaluación lingüística conduce a las representaciones del mundo objetivo, social y del subjetivo (Colomer, 200I, p. 5).

La LI debe tratarse, desde la primera infancia, como un objeto de entretenimiento, goce y disfrute. Durante años se ha mantenido apartada esta idea, $y$ se ha enfocado como una herramienta para el aprendizaje de, por ejemplo, lectura, escritura, comportamiento... Si bien es cierto que todos estos elementos pueden venir dados de forma transversal a ella, no debemos olvidar su principal función, despertar los sentidos, poner nombre a las emociones, potenciarlas y revivirlas, para un mejor conocimiento de sí mismo, de los demás y el entorno, todo sobre una base donde el niño potencie su capacidad imaginativa y creadora. La literatura debe llevarnos donde nuestros pies no pueden, a realidades que podemos conocer, que anhelamos alcanzar, pero que las simples palabras, aquellas que no evocan, que no potencian los sentidos, no pueden crear, ni expresar. Los sentimientos más elevados se reflejan en estos textos. 
Podemos, por tanto, considerar la literatura como el primer contacto del niño con el código escrito desde una perspectiva lúdica y estética, que se va a basar, en un primer momento, en la capacidad innata de captar información a través de los sentidos, lo que provocará reacciones. Por primera vez, y en los momentos sucesivos, podrá ir conociendo, y reconociendo, el entorno, tomando conciencia de él y, lo que es más importante, conociéndose a sí mismo. Es la capacidad de reconocer aquello que le rodea y que capta a través de los sentidos.

Mucho antes de empezar a leer, incluso a hablar con claridad, el niño puede establecer su primer contacto con la literatura a través del cuento narrado por el adulto. $Y$ en esta narración es la imaginación del niño la que pone rostro a los protagonistas de la historia, colores y formas a los escenarios en los que se desarrolla e, incluso, cuando la historia se da por finalizada, si lo ha atrapado, continúa sumido en la creación con el qué pasará después: ivolverá Caperucita a casa de la abuelita a recuperar su capa roja, que Antonio Rodríguez Almodóvar (2004), en su revisión de la obra, hizo que el personaje dejase atrás?

Para que la LI cumpla su objetivo, debe librarse del lastre de su instrumentalización. No podemos pretender que a través de un cuento concebido, por ejemplo, como un manual de las buenas maneras en la escuela, el niño se emocione, se entusiasme. Él espera que nuestras palabras le lleven a conocer realidades lejanas, a descubrir el mundo. Para lograr el gozo estético, la LI debe respetar sus funciones fundamentales y así conseguir el interés de nuestro joven receptor.

Beatriz Hoster, en el material inédito creado para la asignatura El hecho literario y la literatura infantil (del plan de estudios correspondiente al Grado de Ed. Infantil), enumera las funciones fundamentales que debe presentar la LI:

- Suscitar percepciones: construye escenas de gran potencia sensitiva, visual, y sonora que nos ayudan a detenernos en la observación del mundo que nos rodea.

- Provoca emociones: el texto y la ilustración no nos dejan impasibles. Su lectura nos genera tristeza, alegría, ternura, excitación...

- Los personajes ayudan al autoconocimiento: transmiten modelos de relación con los demás y con uno mismo (relacionarlos con la experiencia interior). 
- Ayuda a forjar el lenguaje: palabras precisas, similitudes y oposiciones semánticas, metáforas, construcciones sintácticas inusuales... son recursos expresivos que intensifican las posibilidades comunicativas.

- Humor: transgresión de normas, temas escatológicos, contradicciones...

- Reelaboración literaria: versiones y parodias de obras, temas, personajes y motivos.

- Riqueza temática: conflictos humanos, reflejos de la familia, realidad, valores.

Por supuesto, no todas tienen que aparecer en cada una de las obras de la LI, pero sí es cierto que, en mayor o menor medida, algunas de ellas se vuelven fundamentales según de qué obra se trate. Como ya es habitual (pero también relativamente reciente), los estudiosos de esta materia se distancian de las definiciones que, nos recuerda Cerrillo, se recogían aún en la segunda mitad del siglo pasado. En este caso, retoma las palabras de Martain: El libro infantil nutre la mente con el sentido y el conocimiento de las virtudes naturales, del honor y de la piedad, de la dignidad del hombre y del espíritu de la grandeza y de la dignidad y del destino humano, del entreverarse del bien con el mal, de la "caritas humani generis" (Cerrillo y Sánchez, 2006, p. 68).

Esta visión instrumentalizada quedó atrás hace tiempo. Actualmente se apuesta por la formación de un lector competente desde la primera infancia, a partir del contacto directo con el cuento, haciéndolo suyo, considerándolo accesible, al tiempo que se le ofrece al niño un producto elaborado, que no por sencillo debe ser "simplón".

En nuestra experiencia, nos vamos a centrar principalmente en el análisis de la percepción de estímulos a través de los sentidos por parte los niños de Ed. Infantil, concretamente 5 años, a partir de la observación de la lámina, y el intercambio oral guiado por el adulto. La interpretación de la imagen consigue introducirlos en la narración y atraparlos en la historia. Por tanto, es fundamental la conjugación de un buen texto con un trabajo específico de la ilustración inicial y la posterior lectura intencionada, capaz de transmitir y ayudar al niño a identificar, por sí mismo, los elementos fundamentales por los que esté constituido el cuento. El adulto debe actuar como guía, conduciendo la observación y la interacción verbal en torno a los 
elementos significativos de la ilustración. Pero en ningún caso debe suplir el papel del niño en descifrar lo que hay tras la imagen o el texto. El niño está capacitado para hacerlo por sí mismo con la ayuda del mediador: las "palabras evocadoras" actúan como el interruptor que enciende el pensamiento, lo activan a partir del estímulo de la imagen y ayudan al niño a establecer la relación causa-efecto entre lo que ve y las sensaciones que provocan en él. De esta forma, va construyendo su propia visión del mundo, en sus relaciones con el entorno, con sus semejantes, y consigo mismo. $\mathrm{Va}$ adquiriendo el hábito de reconocer sus propias reacciones relacionándolas con los estímulos que las provocan.

Los niños, en su período de iniciación a la lectura, tienen la capacidad de sentir desde que nacen, como nos recuerda Teresa Durán:

Un niño, al nacer, tiene la misma capacidad sentimental que un adulto. No nos referimos a la misma capacidad de raciocinio, ni a la lógica, que requieren un largo aprendizaje. Pero sí posee la misma intensidad emotiva, la misma intensidad de amor, de odio, de dolor, de justicia..."Siente”, con la misma intensidad que un adulto, los pocos sentimientos para los que está dotado el ser humano-isuerte que son pocos!-, pero no ha desarrollado la misma capacidad para expresarlos (Durán, 2002, p. 27).

Y esta capacidad comienza materializarse a través de lo que perciben por los sentidos:

Al principio, entran en juego las sensaciones, que nos llegan por la percepción sensorial: frío, caliente, blando, duro, claro, oscuro, grande, pequeño, etc. A continuación, estas sensaciones se organizan en sentimientos, que giran alrededor de dos polos: el positivo y el negativo. De este modo entramos en contacto con los conceptos de bueno y malo, bonito y feo, justo e injusto, valiente y cobarde, amor y odio, etc. Y, finalmente, este sencillo sistema binario se ramifica en percepciones que están, de algún modo, por encima del bien y del mal. En este momento podemos hablar de sensibilidad, exquisitez, de refinamiento (Durán, 2002, p. 33).

En la LI impresa, el álbum ilustrado se ha convertido en el principal canal para ponerla en contacto al niño con esta: la conjugación de imágenes cargadas de significación, junto con el texto, cuando aparece, consigue crear un vínculo con el lector difícilmente alcanzable con otros formatos, ya que logra activar todos los sentidos a partir de las evocaciones que produce su visión. Trae a la memoria del lector, a través de los colores, las imágenes, su disposición e incluso la tipografía y 
temas tratados, realidades conocidas o no, que lo comunican con su entorno y con sí mismo. El álbum ilustrado es un producto estético, artístico y, a menudo, didáctico: narra historias o nos transmite emociones, pero también construye un material ideal para formar lectores competentes capaces de enfrentarse a obras complejas (Hoster y Gómez, 2013, p. 66).

En la experiencia de referencia se ha utilizado el álbum Sopa de calabaza (Cooper, 1998), porque como indica T. Durán, consideramos que este formato presenta "una capacidad de comunicación que emana y fluye coherentemente entre la imagen y el texto (...) de una tal especial manera que de ella surge una recepción lectora singular, generalmente no aplicable a otros libros, otros textos, otras imágenes" (Durán, 2008, p. 2).

A continuación, procedemos a explicar, en primer lugar, el método de trabajo utilizado, para posteriormente exponer, paso a paso, el desarrollo del mismo en el aula.

\section{Metodología}

La experiencia objeto de estudio se ha realizado en el Colegio San José (SSCC) de Sevilla, con niños de 5 años, en un aula de E.I de 28 alumnos, repartidos en seis grupos de trabajo cooperativo, método de trabajo explicado del siguiente modo por Johnson and Johnson (1994):

El aprendizaje cooperativo necesita de la participación directa de todos y cada uno de los estudiantes, que trabajan juntos para lograr metas comunes. Se busca el beneficio de uno mismo a la par que el del grupo. Podemos definirlo como el empleo didáctico de grupos reducidos en los que los alumnos trabajan para maximizar su propio aprendizaje y el de los demás (Johnson y Johnson, 1994, p. 5).

Esta definición que realizan Johnson y Johnson, sirve de complemento a la explicación metodológica que nos ofrecía Kagan:

The methods of cooperative learning have certain elements in common that distinguish them from traditional instructional formats, such as the division of the whole class into small teams of students who are made positively interdependent by the systematic application of principles of reward and/or task structure (Kagan, 1985, p. 67). 
El esquema básico de desarrollo de esta actividad es el siguiente:

a) Presentación del mediador y toma de contacto con el grupo.

b) Rutina de pensamiento see, think, wonder, en español conocida por su traducción veo, pienso, me pregunto, a partir de la exposición de la primera lámina del cuento.

Thinking routines are simple patterns of thinking that can be used over and over again and folded easily into learning in the subject areas. They have a public nature, so that they make thinking visible, and students quickly get used to them (Ritchhart , citado por Perkins, 2003, p. 3).

Se caracterizan por ser dinámicas sencillas, de pocos pasos y aplicables en muchas situaciones del aula. Generan implicación y permiten la participación de la totalidad del alumnado. Se pueden desarrollar en grupo o de forma individual, y buscan y alcanzan pensamientos de alto de nivel, con profundas reflexiones, que despiertan la curiosidad del niño y la necesidad de aprender. En resumen, buscan preparar el pensamiento para un aprendizaje más provechoso en cualquier área.

c) Narración del cuento por parte del mediador y proyección para que sea seguido por los alumnos, que observan las láminas que conforman las ilustraciones del cuento mientras que la historia avanza.

d) Folio giratorio.

Es un tipo de estructura cooperativa en la que se reúnen componentes de reflexión personal, activación de esquemas y conocimientos previos. En ella se desarrolla una parte oral y/o escrita, que puede estar estructurada o ser espontánea. En esta experiencia, y porque los alumnos son de 5 años de E.I, la escritura la sustituimos por dibujos. Se desarrollan también las habilidades sociales dado que los alumnos necesitan llegar a acuerdos: qué van a plasmar en el papel, con qué colores, etc. En resumen, el folio giratorio invita a la participación intensa de los alumnos que hablan sobre los materiales que están creando, corrigen entre ellos, reflexionan sobre su aprendizaje, y se evalúan.

e) Exposición de los dibujos realizados (grupo).

En este último paso, se recoge la respuesta de los niños que han participado a 
partir de los dibujos de grupo: se exponen tras haber finalizado el folio giratorio, y cada grupo va explicando a la clase sus interpretaciones, tanto generales (aquellas a las que han llegado tras los comentarios y reflexiones que han surgido espontáneamente durante el desarrollo de la actividad), como particulares (en este caso, las reflexiones que los niños efectúan están más ligadas a su propia experiencia y a aquello que ha producido de forma individual en cada uno de ellos todo el proceso llevado a cabo a través del cuento).

\section{Experiencia realizada con los alumnos de E. I de 5 años (Colegio San} José SS.CC., Sevilla), a partir del cuento Sopa de Calabaza, de Helen Cooper

a) La mediadora se presenta como una contadora de cuentos, que viene a hacer lo que a ella más le gusta: "contar un cuento". Pero necesita que, antes de contar el cuento, los niños le ayuden a averiguar qué es lo que está viendo. Es en este momento en el que se proyecta la lámina (Figura I) y se comienza con la primera tarea: rutina de pensamiento.

La rutina de pensamiento apoya sus bases en poner al alumno en disposición de aprender. Partiendo de la observación, se genera una reflexión y, por último, una/s pregunta/s que obtienen respuesta a través de la adquisición de los nuevos conocimientos. En nuestro caso, la rutina consistió en observación de la lámina, reflexión que verbalizan (qué les sugiere), y por último qué ocurre en la historia (narración). Los alumnos, a través de la observación y descripción de lo que ven, van recibiendo estímulos a través de los sentidos y se sitúan en el interior de la historia. Así surge la necesidad de conocer qué ocurre después.

Con una pregunta objetiva las reflexiones de los oyentes comienzan a manifestarse verbalmente de forma espontánea. En ningún momento el adulto debe caer en la subjetividad, sus aportaciones deben ser mínimas, para que sean los alumnos los que realicen sus indicaciones con la menor influencia posible por parte del que los dirige. (En alumnos de más edad, no es necesario efectuar esta primera pregunta; bastaría invitarlos a describir lo que ven). 


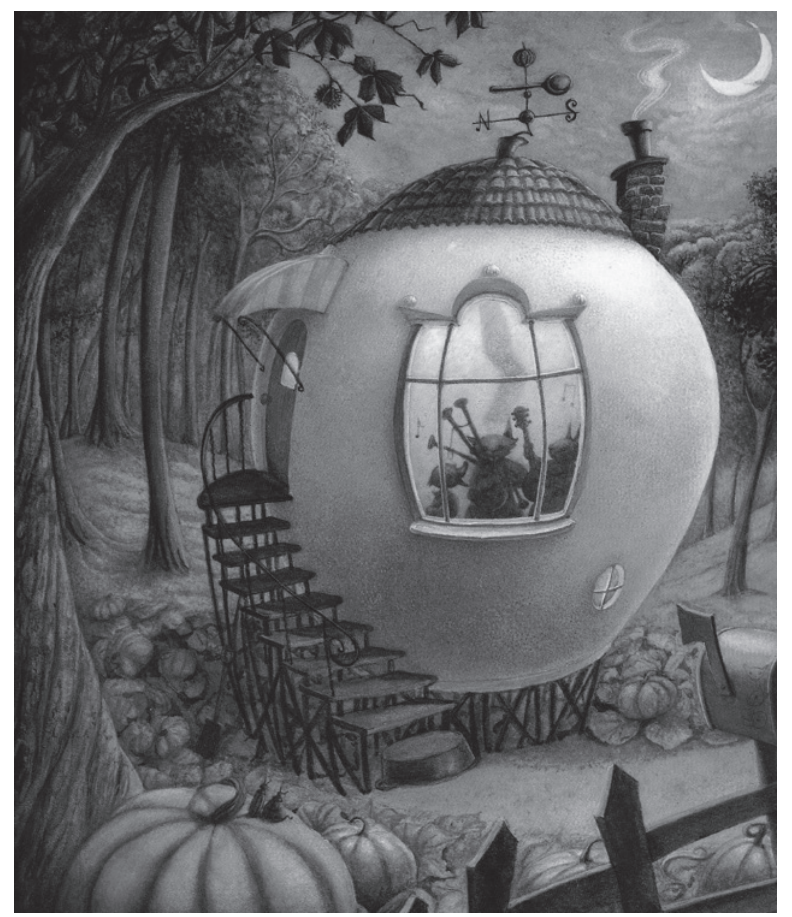

Figura I. Primera ilustración del álbum ilustrado Sopa de calabaza, Helen Cooper.

A continuación se expone en líneas generales el transcurso de la experiencia llevada a cabo.

a. I) Primer paso de la rutina de pensamiento: SEE.

\section{Mediadora: Veo una escalera.}

Se debe partir de una descripción objetiva. A partir de aquí, recogemos las observaciones más comunes de los alumnos: veo...una casa, una chimenea, la luna, luz (en la casa), una veleta, una puerta, una ventana, un bosque, una valla, una calabazas, unos árboles, una escalera, humo, personajes dentro de la casa, una guitarra, veo una ventana pequeña, veo una puerta, veo un toldo, veo un buzón, veo una valla. 
a.2) Segundo paso de la rutina de pensamiento: THINK.

Mediadora: ¿Qué puede haber detrás?

Nace la necesidad de conocer. El mediador introduce la reflexión con: pienso que la luna está porque... es de noche. Esto provoca la sucesión de respuestas generadas desde la percepción de la imagen. En la siguiente tabla (Tabla I), se recogen las respuestas que más se repiten, y las clasificamos según las características que presentan:

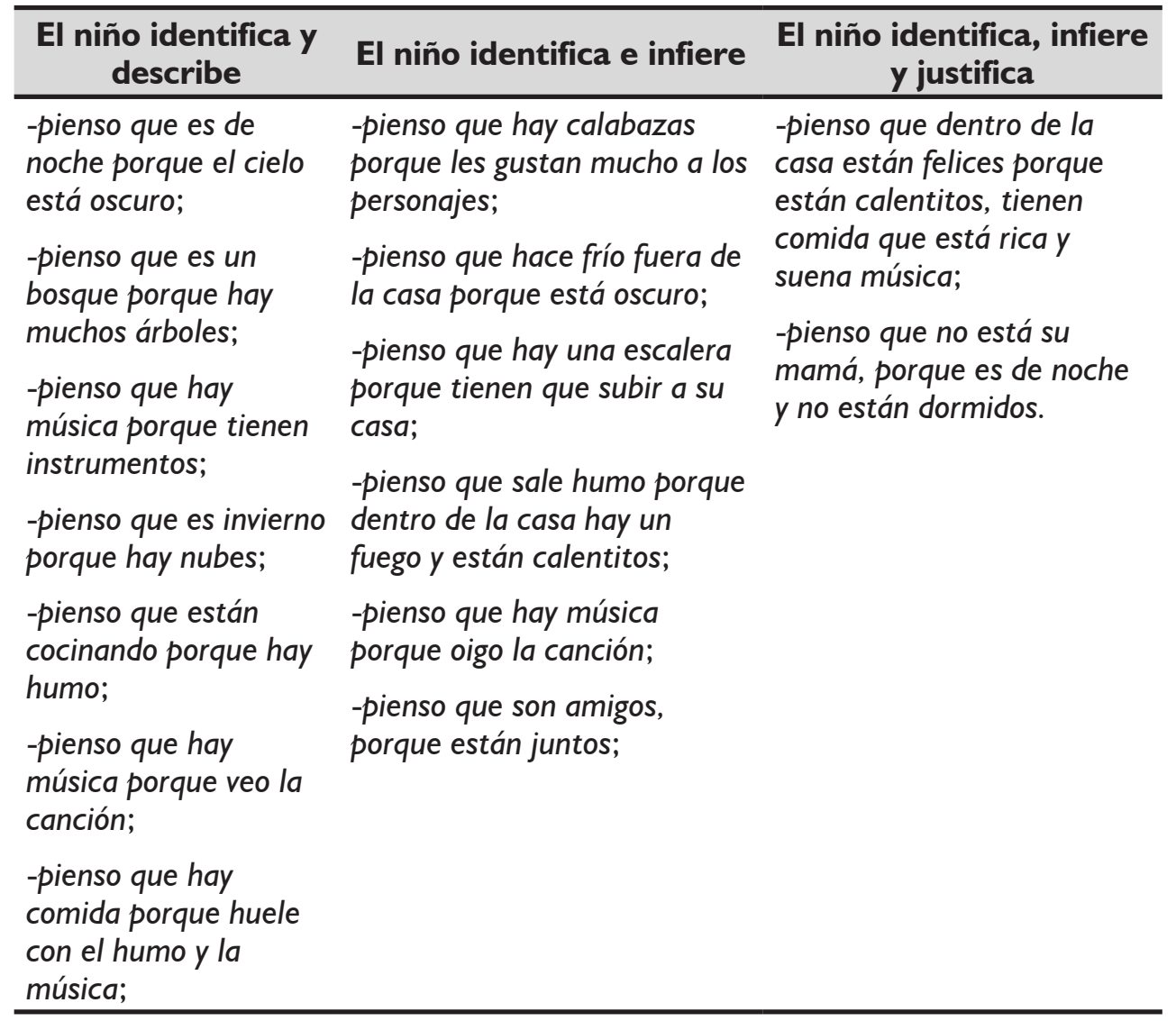

Tabla I. Clasificación de las reflexiones realizadas por los niños en el segundo paso de la rutina de pensamiento. 
Se observa cómo las reflexiones de los niños a partir de la visualización de la primera lámina, encuentran su origen en las percepciones generadas a partir de la imagen.

\section{a.3) Tercer paso: WONDER.}

Ponente: ¿Por qué está ocurriendo esto?

Como recogen Hoster y Gómez, reconocer el tipo de relación que se estable entre la ilustración y el texto en un álbum solo supone un primer paso en el proceso de lectura, pero descubrir el porqué es fundamental para llegar a construir una interpretación más profunda (Hoster y Gómez, 2013, p. 67).

¿Por qué hay una luna? ¿Por qué hay música? ¿Por qué hay luz dentro de la casa? ¿Por qué hay una escalera? ¿Por qué sale música? Del “pienso" al "por qué” los niños pasan solos, la propia reflexión los hace avanzar. La suposición de lo que ocurre provoca que el niño ya no solo se conforme con su reflexión, quiere saber la razón por la que está ocurriendo todo lo observado y percibido, lo que nos sitúa en el momento perfecto para contar la historia, ese momento en que ya no somos nosotros los que demandamos su atención, sino que son ellos los que exigen continuar y saber más. Nos internamos en un método de lectura que ayuda a comprender las percepciones.

Hemos subido juntos la escalera y necesitamos abrir la puerta. ¿Abrimos para saber qué está ocurriendo y entramos al calorcito de la cabaña? ...En medio del bosque hay una vieja cabaña blanca, y un jardín con calabazas. Huele a rica sopa... (Cooper, 1998, p. 3)

b) La experiencia en la lectura del cuento se hace así íntima: los alumnos sienten que son ellos los que están desentrañando el secreto. El narrador del cuento se convierte en una voz, en un focalizador del discurso que, a través de la narración, sitúa en total comunión al niño, la imagen y el texto.

d) Terminada la exposición del cuento, se realiza la estructura cooperativa del folio giratorio. Se pide a los alumnos que saquen un único papel por grupo y un único lápiz. A partir de este momento, cada alumno del grupo dispone de un tiempo determinado (en nuestro caso de 3 a 5 minutos) para dibujar lo que él quiera del cuento, por turnos y en un mismo papel cada grupo. Una vez que la profesora da 
una palmada, el folio pasa al siguiente alumno del grupo, y de esta forma, todos dibujan y participan. Al terminar la primera ronda, realizamos una segunda para colorear los dibujos.

e) Finalmente, se exponen los dibujos en la pizarra, y cada grupo cuenta al resto de la clase qué ha pintado y por qué (a continuación, se recogen algunas de las impresiones expresadas por los niños y observamos los dibujos realizados en grupo cooperativo).

Resumimos las manifestaciones más comunes: el pato es el personaje que más les gusta y se identifican con él porque a veces ellos también se enfadan; reconocen la conducta de querer hacer lo que uno desea por encima de los demás; también reconocen que a veces no dejan a otros hacer lo que ellos desean o que no comparten (se refieren a hermanos y compañeros); han sentido pena cuando el gato lloraba y miedo en el bosque; la casa la describen como bonita y alegre, sienten tranquilidad y felicidad; algunos cuentan que les encanta la sopa que les hace su madre; sienten felicidad cuando los amigos se reencuentran.

Los dibujos que se recogen son los siguientes (Figuras 2, 3, 4, 5, 6, 7)':

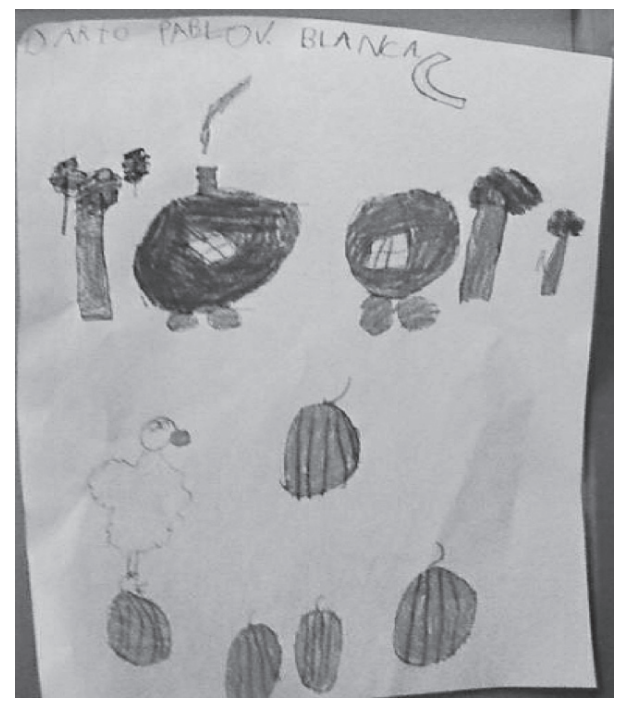

Figura 2. Dibujo del grupo de trabajo número I 


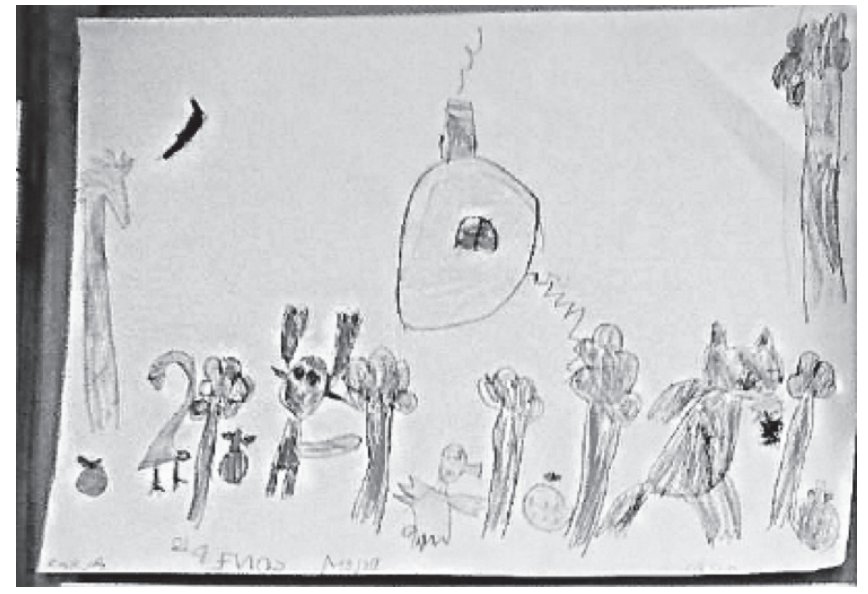

Figura 3. Dibujo del grupo de trabajo número 2

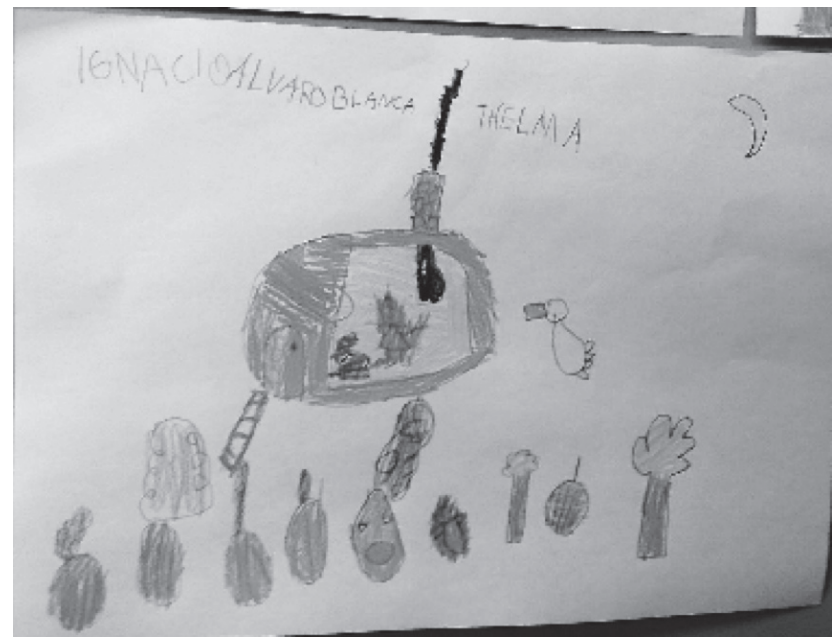

Figura 4. Dibujo del grupo de trabajo número 
172 - Album ilustrado y trabajo cooperativo: las percepciones en educación infantil.

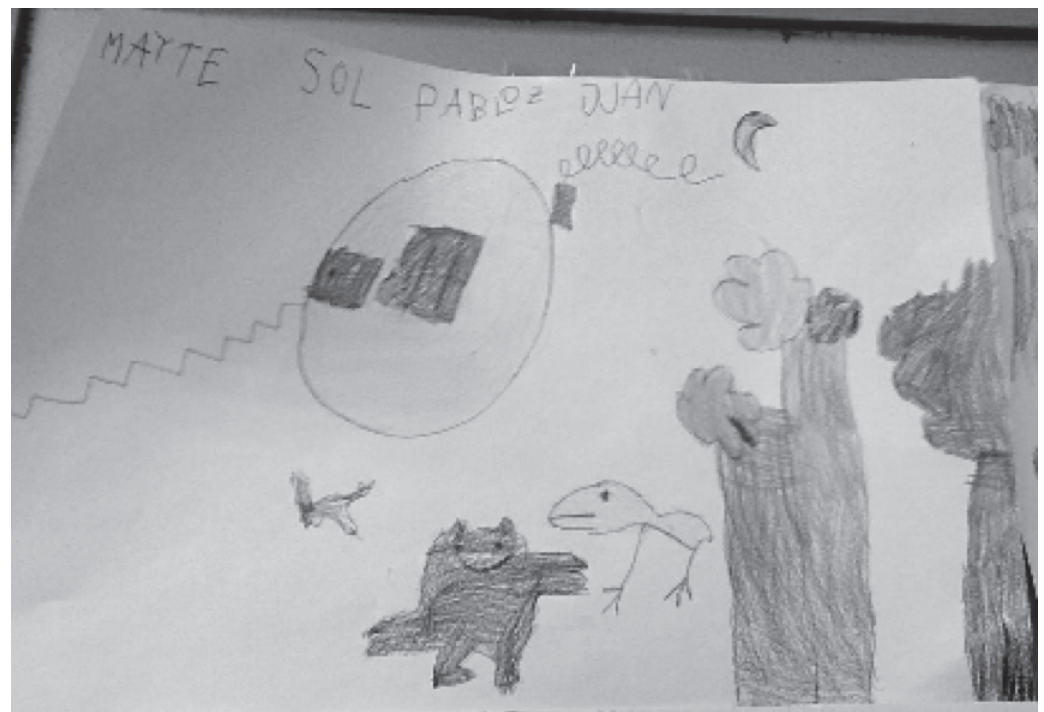

Figura 5. Dibujo del grupo de trabajo número 4

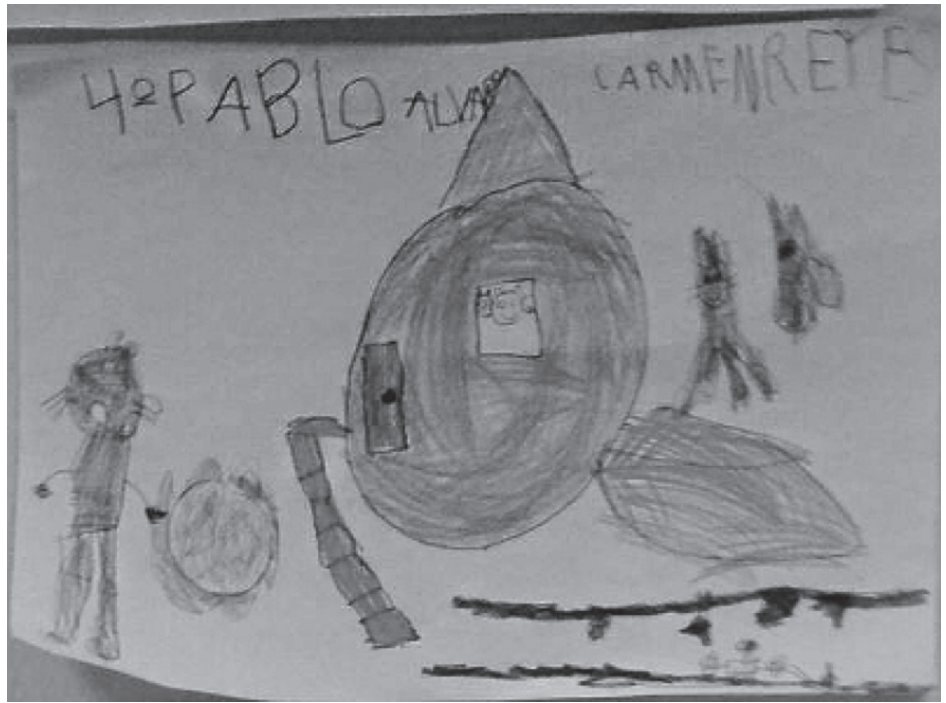

Figura 6. Dibujo del grupo de trabajo número 5 


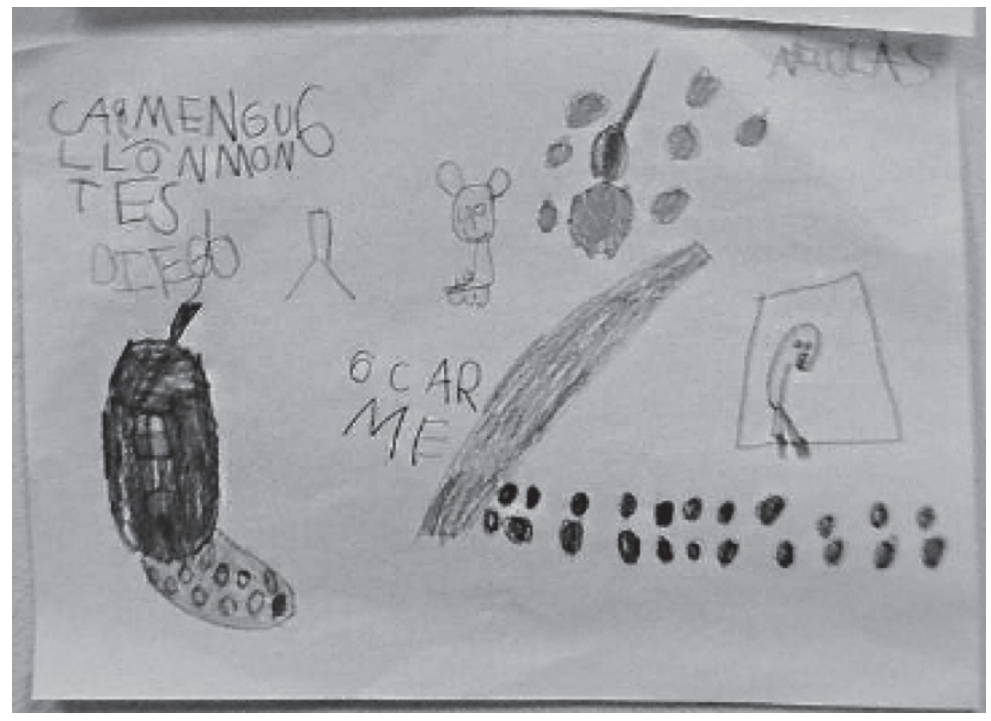

Figura 7. Dibujo del grupo de trabajo número 6

En los dibujos realizados a partir de la estructura de trabajo cooperativo, destacan:

- la presencia de los personajes (protagonistas de la historia)

- los colores del cuento (el niño refleja en sus dibujos los que, según sus percepciones, predominan en la ilustración)

- los árboles (que representan al bosque) y las calabazas (que aparecen de forma recurrente)

- la casa como elemento de cohesión de la historia, donde los tres amigos viven, y donde comienza y termina su aventura (es el elemento central de todos los dibujos; junto a la casa, la escalera, que hemos utilizado para subir, abrir la puerta y entrar en la historia)

- la luna (representada en 4 de los 6 dibujos, y a pesar de que solo aparece en la lámina inicial, y no en el resto del cuento; probablemente, debido al trabajo que de focalización de la atención que se ha realizado sobre esta imagen) 


\section{Conclusión}

Al finalizar la experiencia de trabajo, y tras el análisis de los datos recabados, podemos concluir que, la conjunción de estructuras de trabajo cooperativo junto con el formato de álbum ilustrado, mejora la comprensión de textos orales por parte de los niños. Este hecho se evidencia en los datos recogidos a partir de los dibujos que han realizado en grupos cooperativos. Estos dibujos, a través de su análisis, transmiten las percepciones recibidas por los niños, que atendiendo al álbum trabajado, vemos que son coincidentes con el mismo.

Se observa que a partir de la primera lámina, y sin conocimiento previo de la historia que se les va a contar, los niños reflexionan y exponen ideas que están en relación directa con lo que ocurre posteriormente en la narración, y lo reflejan en las especulaciones que realizan en voz alta durante la rutina de pensamiento (see, think, wonder). Se despierta así la necesidad de avanzar en la historia: quieren saber qué hay después, cuál es la explicación de que esa imagen se presente con esos elementos, colores y forma. Se estimula en ellos la motivación a la lectura y el interés por lo escrito.

Las estrategias de trabajo propuestas y llevadas a cabo generan un clima perfecto para la narración del cuento: ellos, los niños, son los que necesitan escuchar y saber. Se ha preparado al niño, y se le ha ayudado a encontrar motivación para adquirir nuevos conocimientos. Se ha despertado su curiosidad, y sus sentidos están alerta. El mediador desaparece para ellos: su atención se encuentra centrada en la imagen y la narración.

Y cómo el niño observa, piensa y reflexiona se recoge, no solo en lo expresado oralmente, sino a partir de lo dibujado y la coherencia que mantiene con el cuento.

Afirmamos, a partir de la experiencia realizada y expuesta, que esta técnica nos permite trabajar la capacidad de percepción en los niños para el conocimiento del mundo a través de la propia literatura, así como la relación con el entorno y con ellos mismos. Y, por supuesto, para su goce y disfrute, principal función de la LI.

Proponemos, como línea añadida de investigación, otro posible objetivo a alcanzar a través de esta fórmula de trabajo para la animación a la lectura: la aplicación sistemática de estas estrategias en el aula, con un control previo del nivel de comprensión oral del alumnado, y otro posterior tras las intervenciones 
sistemáticas por parte del mediador. De esta forma, podríamos medir la eficacia real de esta técnica de acercamiento al cuento, y de motivación a la lectura, con la finalidad de mejorar la competencia en comprensión oral.

\section{Bibliografía}

\section{I. Referencias}

Cerrillo, P. y Sánchez, C. (2006). Literatura con mayúsculas. Revista Ocnos, 2, 7-2I .

Colomer, T. (200I). La enseñanza de la literatura como construcción del sentido. Lectura y vida, 22, 2-19.

Durán, T. (2002). Leer antes de leer. Salamanca: Anaya.

Durán, T. (2008). Aprendiendo de los álbumes. En Actas do $7^{\circ}$ Encontro Nacional $/ 5^{\circ}$ Internacional de Investigação em Leitura, Literatura Infantil e llustração (pp.4864). Braga: Universidade do Minho.

Hoster, B. y Gómez, A. (20 I3). Interpretación de álbumes ilustrados como recurso educativo para la competencia literaria y visual. Red Visual, 19, 65-76.

Johnson, D. y Johnson, R. ( 1 994). El aprendizaje cooperativo. Barcelona: Paidós SAICF.

Mendoza, A. (1999). Función de la literatura infantil y juvenil en la formación de la competencia literaria. En P. Cerrillo y J. García Padrino, Literatura infantil y su didáctica (pp. I I-53). Cuenca: Ediciones de la Universidad de Castilla la Mancha.

Kagan, S. (1985). Dimenssions of cooperative Classroom Structures. En R. HertzLazarowitz, S. Kagan, S. Sharan, R. Slavin y C. Webb (Eds.), Learning to cooperate. Cooperating to learn (pp. 67-96). New York: Springer.

Perkins, D. (2003). Making thinking visible. Project Zero. Recuperado el 04/ I I/20 I 6 de < http://www.pz.harvard.edu/sites/default/files/MakingThinkingVisible_DP.pdf > .

Rodríguez, A. (2004). La verdadera historia de Caperucita. Sevilla: Kalandraca Ediciones Andalucía. 


\subsection{Texto literario}

Cooper, H. (1998). Sopa de calabaza. Barcelona: Juventud.

Rodríguez, A. (2004). La verdadera historia de Caperucita. Sevilla: Kalandraca Ediciones Andalucía.

\section{NOTA EDITORIAL}

I. A pesar de la baja resolución de las imágenes, se ha considerado interesante su reproducción como muestras de la actividad infantil descrita en el artículo. 